\title{
衝撃外圧力を受ける複合材料積層円筒殼の動的安定性*
}

\author{
粕 谷 平 和*1, 松 岡 一 雄*2

\section{Dynamic Stability of Composite Laminated Cylindrical Shells under Impact External Pressure}

\author{
Hirakazu KASUYA*3 and Kazuo MATSUOKA \\ ${ }^{* 3}$ Tokai University, Dept. of Prime Mover Engineering, \\ Kitakaname 1117. Hiratsuka-shi Kanagawa, 259-1292 Japan
}

\begin{abstract}
Because of their high specific strength and stiffness, fiber-reinforced plastics have been used as structural members in various fields, and hence analysis of thin laminated structures is important. In this paper, the problem of dynamic stability of cross ply laminated cylindrical shells under impact external pressure is described. First of all, the motion of cylindrical shells under impact external pressure is defined as axially symmetric motion. Following this definition, certain perturbations are superimposed on this motion and their effect on the behavior of the shell is investigated. The symmetric state of motion of the shell is called stable if the perturbations remind bounded. The solutions for the prebuckling motion and the perturbed motion are obtained using the Galerkin's method. Stable regions are examined by utilizing the Mathieu's equation. The inevitability of dynamically unstable behaviors is proved analytically and the effects of various factors, such as external pressure ratio, number of layers, lamination constitution, dynamic unstable mode and dimensions of the cylinder, are clarified.
\end{abstract}

Key Words: Structural Analysis, Composite Materials, Dynamic Stability, CFRP, Cross-Ply Laminated Cylindrical Shell, Impact External Pressure, Mathieu's Equation

\section{1. 緒言}

CFRP などに代表される高性能複合材料は, 高比強 度, 高比剛性の優れた性能を生かし, 航空機や宇宙機 器などの構造物の軽量化に対する要求に適用されてい る.また, それらの要求のために, 構造の薄肉化が図 られる場合，このような円筒殻構造には衝撃荷重が作 用することが多いことを考慮すると, 円筒款の動的安 定性を解析することが重要な課題である(1) (3).

動的荷重を受ける円筒殻の安定性問題に関して，そ の不安定領域を明らかにすることが主要な課題であ り, 不安定領域を Mathieu 形方程式で示しているも のが数多くある，その中でも，著者らは前報(4) (6)に おいて, 衝撃軸圧縮荷重の継続時間が十分に長い場合, 座屈前軸対称運動を考えることにより静的座屈值以下 でも不安定になる可能性のあることを示している.

そこで本論文では，雨端単純支持された対称クロス

プライ積層円筒殼が衝揧外圧力を受ける場合につい

て，基礎方程式から Mathieu 形方程式を導き, Math-

* 原稿受付 1999 年 1 月 $18 \mathrm{H}$.

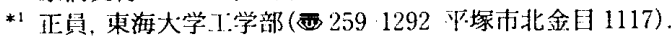

*2 学生員, 東海大学大学院.

E mail : kasuya@ keyaki.cc.u tokai.ac.jp ieu 形方程式の安定判別を用い, 静的座屈値以下の衝 撃荷重を負荷させた場合でも，不安定モードが発生す ることを明らかにする，また，不安定現象に与える諸 因子, 例えば, 積層順序, 積層数, 形状パラメー夕, 負 荷条件などの影響を解析的手法によって検討する。

\section{2. 理論的解析法}

$2 \cdot 1$ 基礎式 図 1 に示すような半径 $R$, 筒長 $L$, 板厚 $h$ の複合材料積層门筒殻が半径力向に均一な衝 撃外圧力 $p(t)$ を受ける場合を考える，座標原点を円 筒殻の中央にとり, 軸方向, 円周方向, 板厚方向にそ れぞれ $x, y, z$ 軸をとる. 円筒殼の中央面に扔ける面 内ひずみ成分 $\varepsilon_{x}, \varepsilon_{y}, \gamma_{x y}$, 曲率成分 $\kappa_{x} . \kappa_{y}, \kappa_{x y}$ と変位 成分 $u, v, w$ との関係を二次の微小項を考虑した Donnell の有限変形理論を用いると非線形となり次式 のように表される。

$$
\left.\begin{array}{l}
\varepsilon_{x}=\frac{\partial u}{\partial x}+\frac{1}{2}\left(\frac{\partial w}{\partial x}\right)^{2}, \varepsilon_{y}=\frac{\partial v}{\partial y}+\frac{w}{R}+\frac{1}{2}\left(\frac{\partial w}{\partial y}\right)^{2} \\
\gamma_{x y}=\frac{\partial u}{\partial y}+\frac{\partial v}{\partial x}+\frac{\partial w}{\partial x} \frac{\partial w}{\partial y}
\end{array}\right\}
$$


面内ひずみ成分と平面応力成分との関係は，弾性限度 内に限定すると次式のように表される。

$$
\varepsilon_{x}=\frac{\sigma_{x}}{E_{x}}-\frac{\nu_{y} \sigma_{y}}{E_{y}}, \varepsilon_{y}=\frac{\sigma_{y}}{E_{y}}-\frac{\nu_{x} \sigma_{x}}{E_{x}}, \gamma_{x y}=\frac{\tau_{x y}}{G_{x y}}
$$

ここで, $E_{x}, E_{y}$ はヤング率, $G_{x y}$ はせん断剛性率, $\nu_{x}$, 放はポアソン比である。また，今解析モデルの対称 クロスプライ積層の合応力成分, 合モーメント成分と 面内ひずみ成分，曲率との関係は次式で表される。

$$
\begin{aligned}
& \left\{\begin{array}{l}
N_{x} \\
N_{y} \\
N_{x y}
\end{array}\right\}=\left[\begin{array}{ccc}
A_{11} & A_{12} & 0 \\
A_{12} & A_{22} & 0 \\
0 & 0 & A_{66}
\end{array}\right]\left\{\begin{array}{l}
\varepsilon_{x} \\
\varepsilon_{y} \\
\gamma_{x y}
\end{array}\right\} \\
& \left\{\begin{array}{l}
M_{x} \\
M_{y} \\
M_{x y}
\end{array}\right\}=\left[\begin{array}{ccc}
D_{11} & D_{12} & 0 \\
D_{12} & D_{22} & 0 \\
0 & 0 & D_{66}
\end{array}\right]\left\{\begin{array}{l}
\varkappa_{x} \\
\varkappa_{y} \\
\varkappa_{x y}
\end{array}\right\}
\end{aligned}
$$

ここで, $A_{i j}$ は伸張剛性マトリックス, $D_{i j}$ は曲げ剛性 マトリックスであり，それぞれーノ向強化材の繊維方 向, 織維に洫角方向の弾性筀数 $E_{L}, E_{T}$, ポアソン比 $\nu_{L}, \nu_{T}$ およびせん断骩性率 $G_{L T}$ が与えられると求め られる。そして，板幂方向の慣性力のみを考虑すると， 面内および板厚方向の平衡方程式はそれぞれ次式で表 される。

$$
\begin{aligned}
& \frac{\partial N_{x}}{\partial x}+\frac{\partial N_{x y}}{\partial y}=0, \frac{\partial N_{x y}}{\partial x}+\frac{\partial N_{y}}{\partial y}=0 \cdots \cdots \cdots \cdot \\
& \frac{\partial^{2} M_{x}}{\partial x^{2}}+2 \frac{\partial^{2} M_{x y}}{\partial x \partial y}+\frac{\partial^{2} M_{y}}{\partial y^{2}}-\frac{N_{y}}{R}+N_{x} \frac{\partial^{2} w}{\partial x^{2}} \\
& \quad+N_{y} \frac{\partial^{2} u}{\partial y^{2}}+2 N_{x y} \frac{\partial^{2} w}{\partial x \partial y}=\rho h \frac{\partial^{2} w}{\partial t^{2}}+p(t)
\end{aligned}
$$

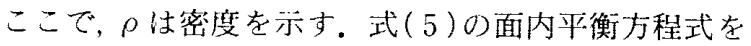
満足する応力関数 $F$ を次のように定義する.

$$
N_{x}=h \frac{\partial^{2} F}{\partial y^{2}}, N_{y}=h \frac{\partial^{2} F}{\partial x^{2}}, N_{x y}=-h \frac{\partial^{2} F}{\partial x \partial y} \text {. }
$$

上式 $(7)$ の夋力関数 $F$ と合モーメント成分を板厚力 向の平衡方程式に代入すると，

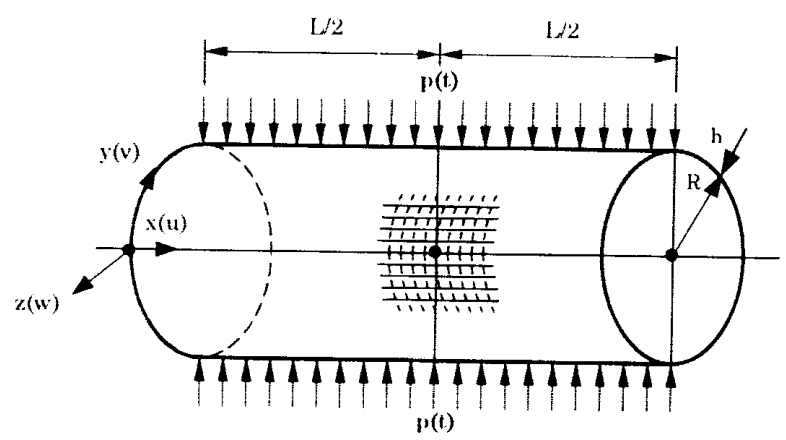

Fig. 1 Configuration and coordinates of composite laminated cylindrical shell

$$
\begin{gathered}
D_{11} \frac{\partial^{4} w}{\partial x^{4}}+2\left(D_{12}+2 D_{66}\right) \frac{\partial^{4} w}{\partial x^{2} \partial y^{2}}+D_{22} \frac{\partial^{4} w}{\partial y^{4}} \\
+\frac{h}{R} \frac{\partial^{2} F}{\partial x^{2}}-h \frac{\partial^{2} F}{\partial y^{2}} \frac{\partial^{2} w}{\partial x^{2}}-h \frac{\partial^{2} F}{\partial x^{2}} \frac{\partial^{2} w}{\partial y^{2}} \\
+2 h \frac{\partial^{2} F}{\partial x \partial y} \frac{\partial^{2} w}{\partial x \partial y}+\rho h \frac{\partial^{2} w}{\partial t^{2}}+p(t)=0
\end{gathered}
$$

となり, 式(1)加変位 $u, v$ を消去し, 式 (2) と忍力 関数 $F$ で整理すると適合条件式が次式のようになる。

$$
\begin{gathered}
E_{x} \frac{\partial^{4} F}{\partial x^{4}}-\left(2 \nu_{x} E_{y}-\frac{E_{x} E_{y}}{G_{x y}}\right) \frac{\partial^{4} F}{\partial x^{2} \partial y^{2}}+E_{y} \frac{\partial^{4} F}{\partial y^{4}} \\
=E_{x} E_{y}\left\{\frac{1}{R} \frac{\partial^{2} w}{\partial x^{2}}+\left(\frac{\partial^{2} w}{\partial x \partial y}\right)^{2}-\frac{\partial^{2} w}{\partial x^{2}} \frac{\partial^{2} w}{\partial y^{2}}\right\}
\end{gathered}
$$

円筒款に荷重が作用したとき, 初期に起こる運動は 軸対称連動を仮定し, 初期運動に添字 $A$ を付けて表 すと,

$$
u_{A}=u_{A}(x, t), v_{A}=0, w_{A}=w_{A}(x, t)
$$

となり，初期運動の板厚方向の平衡方程式は次式のよ うに変挨される。

$$
H\left(w_{A}\right) \equiv D_{11} \frac{\partial^{4} w_{A}}{\partial x^{4}}+E_{y} \frac{w_{A} h}{R^{2}}+p(t)+\rho h \frac{\partial^{2} w_{A}}{\partial t^{2}}=0
$$

初期運動の安定，不安定を論ずるために，この運動 に微小擾乱を与え, その時間に対する変化を調べる。 この擾乱に添字 $B$ を付けて表すと擾乱の加わった連 動は,

$$
u=u_{A}+u_{B}, v=v_{A}+v_{B}, w=w_{A}+w_{B}
$$

となる。ここで, $u_{B}, v_{B}, w_{B}$ は $x, y, t$ の関数である。 㨨乱変位 $u_{B}, v_{B}, w_{B}$ を微小であると仮定し, 式(8), （9）に代入して非線形項を省略すると，損乱成分に関 军る平衡方程式抢よび適合条件式が得られる。

$$
\begin{aligned}
& I\left(w_{B}\right)=D_{11} \frac{\partial^{4} w_{B}}{\partial x^{4}}+2\left(D_{12}+2 D_{66}\right) \frac{\partial^{4} w_{B}}{\partial x^{2} \partial y^{2}} \\
& +D_{22} \frac{\partial^{4} w_{B}}{\partial y^{4}}-E_{y} h \frac{w_{A}}{R} \frac{\partial^{2} w_{B}}{\partial y^{2}}+\frac{h}{R} \frac{\partial^{2} F_{B}}{\partial x^{2}} \\
& \quad-h \frac{\partial^{2} w_{A}}{\partial x^{2}} \frac{\partial^{2} F_{B}}{\partial y^{2}}+\rho h \frac{\partial^{2} w_{B}}{\partial t^{2}}=0 \quad \cdots \cdots \cdots \cdots(13) \\
& E_{x} \frac{\partial^{4} F_{B}}{\partial x^{4}}\left(2 \nu_{x} E_{y}-\frac{E_{x} E_{y}}{G_{x y}}\right) \frac{\partial^{4} F_{B}}{\partial x^{2} \partial y^{2}}+E_{y} \frac{\partial^{4} F_{B}}{\partial y^{4}}
\end{aligned}
$$

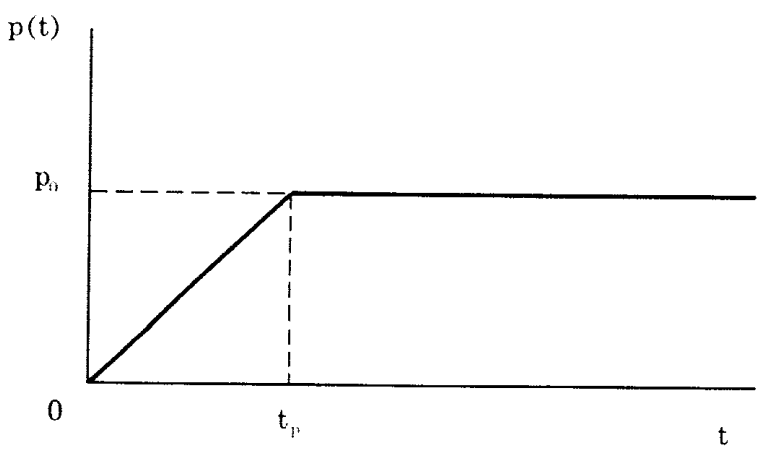

Fig. 2 Load condition 
1910

$$
=E_{x} E_{y}\left\{\frac{1}{R} \frac{\partial^{2} w_{B}}{\partial x^{2}}-\frac{\partial^{2} w_{A}}{\partial x^{2}} \frac{\partial^{2} w_{B}}{\partial y^{2}}\right\}
$$

境界条件は, 両端単純支持を想定し, 円筒殼両端 $x=$ $\pm L / 2$ の条件は, 次のようになる.

$$
w=0, \frac{\partial^{2} w}{\partial x^{2}}=0, N_{x B}=0, v_{B}=0
$$

$2 \cdot 2$ 荷重条件 丹筒殻に作用する外圧力 $p(t)$ の 荷重条件を次式で示し, 状態図を図 2 に示す。

$$
\begin{aligned}
& p(t)=p_{0} \frac{t}{t_{p}} \quad\left(0 \leqq t \leqq t_{p}\right) \\
& p(t)=p_{0} \quad\left(t \geqq t_{p}\right) \cdots \ldots \ldots . . .
\end{aligned}
$$

つまり, 外圧力が $t=0$ から作用し， $0 \leqq t \leqq t_{p}$ で直線 的に作用し， $t_{p}$ 時間後一定值 $p_{0}$ に保たれる.ここで は荷重の継続時間を無限と仮定している.

$2 \cdot 3$ 初期運動 式(11)で示した初期運動の平衡 方程式の近似解を求めるにあたり， $w_{A}$ の波形として 静的に $p_{0}$ が作用した場合を考え， $w_{A}$ を次式で仮定す る。

$$
\begin{aligned}
w_{A} & =a(t) h\left\{1+A_{1} \sin a_{1} x \sinh a_{2} x\right. \\
& \left.+A_{2} \cos a_{1} x \cosh a_{2} x\right\}
\end{aligned}
$$

ここで,

$$
a_{1}=a_{2}=\sqrt{\frac{1}{2 R} \sqrt{\frac{1}{D_{11}}\left(A_{22}-\frac{A_{12}^{2}}{A_{11}}\right)}}
$$

円筒殻に作用する衝撃外圧力 $p_{0}$ と外圧力を受ける対 称クロスプライ積層円筒款の非対称変形を星する静的 座屈值 $p_{s}$ との比を荷重比 $I$ とする，また，外生力を 受ける対称クロスプライ積層円筒款の非対称変形を呈 する静的座屈值 $p_{s}$ は, 次式で示される(7)(8).

$I=p_{0} / p_{s}$

$p_{s}=\frac{1}{R}\left(\frac{R}{n_{p}}\right)^{2}\left(T_{33}\right.$

$$
\left.+\frac{2 T_{12} T_{13} T_{23}-T_{11} T_{23}^{2}-T_{22} T_{13}^{2}}{T_{11} T_{22}-T_{12}^{2}}\right)=[T]
$$

ここで,

$$
\begin{aligned}
T_{11} & =A_{11}\left(\frac{m_{p} \pi}{L}\right)^{2}+A_{66}\left(\frac{n_{p}}{R}\right)^{2} \\
T_{12} & =\left(A_{12}+A_{66}\right)\left(\frac{m_{p} \pi}{L}\right)\left(\frac{n_{p}}{R}\right) \\
T_{22} & =A_{22}\left(\frac{n_{p}}{R}\right)^{2}+A_{66}\left(\frac{m_{p} \pi}{L}\right)^{2} \\
T_{13} & =-\frac{A_{12}}{R}\left(\frac{m_{p} \pi}{L}\right), T_{23}=-\frac{A_{22}}{R}\left(\frac{n_{p}}{R}\right) \\
T_{33} & =D_{11}\left(\frac{m_{p} \pi}{L}\right)^{4}+2\left(D_{12}+2 D_{66}\right)\left(\frac{m_{p} \pi}{L}\right)^{2} \\
\quad & \times\left(\frac{n_{p}}{R}\right)^{2}+D_{22}\left(\frac{n_{p}}{R}\right)^{4}+\frac{A_{22}}{R^{2}}
\end{aligned}
$$

であり，式(20)は，殼の材料定数のほかに形状パラメ 一夕の関数であり, 各種の波数 $\left(m_{p}, n_{p}\right.$; 軸方向半波 数, 円周方向波数）の整数值に対する最小値が外圧座 屈圧力となる.

一方，無次元量 $\alpha_{1}, \alpha_{2}$ を次のように定める.

$$
\alpha_{1}=a_{1} L / 2, \alpha_{2}=a_{2} L / 2
$$

また，式(17)中の $A_{1}, A_{2}$ は式(15)の境界条件から

$$
\left.\begin{array}{l}
A_{1}=-\frac{2 \alpha_{1} \alpha_{2} \sin \alpha_{1} \sinh \alpha_{2}}{2 \alpha_{1} \alpha_{2}\left(\cosh ^{2} \alpha_{2}-\sin ^{2} \alpha_{1}\right)} \\
A_{2}=-\frac{2 \alpha_{1} \alpha_{2} \cos \alpha_{1} \cosh \alpha_{2}}{2 \alpha_{1} \alpha_{2}\left(\cosh ^{2} \alpha_{2}-\sin ^{2} \alpha_{1}\right)}
\end{array}\right\}
$$

となる。

$a(t)$ を求めるため, 式(17)の $w_{A}$ を式(11)に代入し, Galerkin 法

$\int_{-L / 2}^{L / 2} H\left(w_{A}\right)\left(1+A_{1} \sin a_{1} x \sinh a_{2} x+A_{2} \cos a_{1} x \cosh a_{2} x\right) d x=0$

を用いると，

$$
\rho h^{2}\left(Y_{0}+A_{1} Y_{1}+A_{2} Y_{2}\right) \frac{d^{2} a(t)}{d t^{2}}+h\left\{\frac{E_{y} h}{R^{2}}\left(Y_{0}+A_{1} Y_{1}+A_{2} Y_{2}\right)+\left(\frac{2}{L}\right)^{4} D_{11}\left(C_{1} Y_{1}+C_{2} Y_{2}\right)\right\} a(t)+p(t) Y_{0}=0
$$

ただし、

$B_{1}=-\left\{\left(\alpha_{1}^{2}-\alpha_{2}^{2}\right) A_{1}+2 \alpha_{1} \alpha_{2} A_{2}\right\}, B_{2}=2 \alpha_{1} \alpha_{2} A_{1}-\left(\alpha_{1}^{2}-\alpha_{2}^{2}\right) A_{2}$

$C_{1}=\left(\alpha_{1}^{4}-6 \alpha_{1}^{2} \alpha_{2}^{2}+\alpha_{2}^{2}\right) A_{1}+4 \alpha_{1} \alpha_{2}\left(\alpha_{1}^{2}-\alpha_{2}^{2}\right) A_{2}, C_{2}=-4 \alpha_{1} \alpha_{2}\left(\alpha_{1}^{2}-\alpha_{2}^{2}\right) A_{1}+\left(\alpha_{1}^{4}-6 \alpha_{1}^{2} \alpha_{2}^{2}+\alpha_{2}^{4}\right) A_{2}$

$Y_{0}=1+\left\{\left(A_{1} \alpha_{2}+A_{2} \alpha_{1}\right) \sin \alpha_{1} \cosh \alpha_{2}-\left(A_{1} \alpha_{1}-A_{2} \alpha_{2}\right) \cos \alpha_{1} \sinh \alpha_{2}\right\} /\left(\alpha_{1}^{2}+\alpha_{2}^{2}\right)$

$Y_{1}=\frac{\alpha_{2} \sin \alpha_{1} \cosh \alpha_{2}-\alpha_{1} \cos \alpha_{1} \sinh \alpha_{2}}{\alpha_{1}^{2}+\alpha_{2}^{2}}-\frac{A_{1}}{8}\left(2-\frac{\sin 2 \alpha_{1}}{\alpha_{1}}-\frac{\sinh \alpha_{2}}{\alpha_{2}}\right)$

$-\left\{\left(A_{1} \alpha_{1}-A_{2} \alpha_{2}\right) \sin 2 \alpha_{1} \cosh 2 \alpha_{2}+\left(A_{1} \alpha_{2}+A_{2} \alpha_{1}\right) \cos 2 \alpha_{1} \sinh 2 \alpha_{2}\right\} /\left(8\left(\alpha_{1}^{2}+\alpha_{2}^{2}\right)\right)$

$Y_{2}=\frac{\alpha_{1} \sin \alpha_{1} \cosh \alpha_{2}+\alpha_{2} \cos \alpha_{1} \sinh \alpha_{2}}{\alpha_{1}^{2}+\alpha_{2}^{2}}+\frac{A_{1}}{8}\left(2+\frac{\sin 2 \alpha_{1}}{\alpha_{1}}+\frac{\sinh \alpha_{2}}{\alpha_{2}}\right)$

$+\left\{\left(A_{1} \alpha_{2}+A_{2} \alpha_{1}\right) \sin 2 \alpha_{1} \cosh 2 \alpha_{2}-\left(A_{1} \alpha_{1}-A_{2} \alpha_{2}\right) \cos 2 \alpha_{1} \sinh 2 \alpha_{2}\right\} /\left(8\left(\alpha_{1}^{2}+\alpha_{2}^{2}\right)\right)$ 
時間 $t, t_{p}$ を次のように無次元化する。

$$
\tau=\frac{t}{R} \sqrt{\frac{E_{y}}{\rho}}, \quad \tau_{p}=\frac{t_{p}}{R} \sqrt{\frac{E_{y}}{\rho}}
$$

式(16・a)を式(25)に代入して,

$$
\begin{aligned}
& \frac{d^{2} a(\tau)}{d \tau^{2}}+\left(q+r \frac{\tau}{\tau_{p}}\right) a(\tau)+s \frac{\tau}{\tau_{p}}=0, \quad 0 \leqq \tau \leqq \tau_{p} \\
& \frac{d^{2} a(\tau)}{d \tau^{2}}+(q+r) a(\tau)+s=0, \quad \tau \geqq \tau_{p}
\end{aligned}
$$

ここで, $q, r, s$ は次のようになる。

$$
\left.\begin{array}{l}
q=1+\frac{D_{11}}{h} \frac{R^{2}}{E_{y}}\left(\frac{2}{L}\right)^{4} \frac{C_{1} Y_{1}+C_{2} Y_{2}}{Y_{0}+A_{1} Y_{1}+A_{2} Y_{2}} \\
r=0, s=\left(\frac{R}{h}\right)^{2} \frac{[T]}{E_{y}} \frac{Y_{0}}{Y_{0}+A_{1} \bar{Y}_{1}+A_{2} Y_{2}} I
\end{array}\right\}
$$

初期条件注，

$$
\tau=0 て ゙, a(\tau)=0, d a(\tau) / d \tau=0
$$

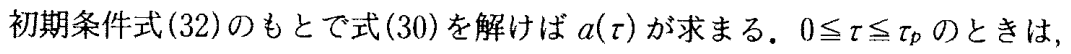

$$
a(\tau)=\sum_{k=1}^{\infty} a_{k}^{*}\left(\frac{\tau}{\tau_{p}}\right)^{k}
$$

なる級数展開を行い, 式(33)を式 $(30 \cdot \mathrm{a})$ に代人して係数比較することにより $a_{k}^{*} か ゙$ 求まる. 初期条件式(32)を考慮 すると，

$$
a_{1}^{*}=0, a_{2}^{*}=0, a_{3}^{*}=-\frac{s \tau_{p}^{2}}{6}, a_{k}^{*}=-\frac{\left(q a_{k-2}^{*}+r a_{k-3}^{*}\right) \tau_{p}^{2}}{k(k-1)} \quad(k=4,5,6, \cdots)
$$

となる. $\tau=\tau_{p}$ のときの $a(\tau), d a(\tau) / d \tau$ の值をそれぞれ $\xi_{1}, \xi_{2}$ とすれば,

$$
\xi_{1}=a\left(\tau_{p}\right)=\sum_{k=1}^{\infty} a_{k}^{*}, \xi_{2}=\left(\frac{d a(\tau)}{d \tau}\right)_{\tau=\tau_{p}}=\sum_{k=1}^{\infty} \frac{a_{k}^{*} k}{\tau_{p}}
$$

が導かれる.一方， $\tau \geqq \tau_{p}$ のときは，式 $(30 \cdot \mathrm{b})$ から

$$
a(\tau)=K\{1-\alpha \cos (\Omega \tau+\delta)\}
$$
ただし，

$$
K=-\frac{s}{q+r}, \quad \Omega=\sqrt{q+r} .
$$

が導かれる， $\alpha, \delta$ は末定係数で式(35)から求まる。すなわち

$$
\alpha=\sqrt{\left(\frac{\xi_{1}}{K}-1\right)^{2}+\left(\frac{\xi_{2}}{K \Omega}\right)^{2}}, \quad \delta=\cos ^{-1}\left\{\frac{1}{\alpha}\left(1-\frac{\xi_{1}}{K}\right)\right\}-\Omega \tau_{p}
$$

となる。

$2 \cdot 4$ 初期運動の安定判別初期運動の安定, 不安定を論ずるにあたり, 微小摱乱 $u_{B}, v_{B}, w_{B}$ を初期運動に加 え，その不安定現象を調べる．境界条件式(15)を満足する変形样式として， $w_{B}, F_{B}$ を次式で仮定する.

$$
\begin{aligned}
& w_{B}=b(t) h \cos (m \pi x / L) \sin (n y / R) \\
& F_{B}=f_{B}(x, t) \sin (n y / R)
\end{aligned}
$$

ここで, $m$ は軸方向半波数, $n$ は円周方向波数を表す(ただし， $m:$ 奇数, $n:$ 整数). 満たすべき残りの境界条件 は、式(15)の後者から雨端で,

$$
\left(\partial^{2} F_{B} / \partial x^{2}\right)=\left(\partial^{2} F_{B} / \partial y^{2}\right)=0
$$

が導かれる。

$2 \cdot 5$ 擾乱の方程式 $\tau \geqq \tau_{p} に お け る$ 初期運動の安定性問題を考える.したがって, 式(14)を満足すべき $f_{B} を$ 求め, 式 $(39)$ に代人すると, 忍力関数 $F_{B}$ が以下のように求められる.

$$
\begin{aligned}
& F_{B}=\frac{E_{y} L^{2} h}{R} b(t)\left[-\frac{(m \pi)^{2}}{(m \pi)^{4}+k^{2}(L m \pi)^{2}+(l L)^{4}} \cos \left(\frac{m \pi x}{L}\right)+a(t) \frac{n^{2}}{4} \frac{h}{R}\left\{F_{1} \cosh m_{1} x+F_{2} \cosh m_{2} x\right.\right. \\
& +H_{1} \sin \left(a_{1}+\frac{m \pi}{L}\right) x \sinh a_{2} x+H_{2} \sin \left(a_{1}-\frac{m \pi}{L}\right) x \sinh a_{2} x+J_{1} \cos \left(a_{1}+\frac{m \pi}{L}\right) x \cosh a_{2} x \\
& \left.\left.+J_{2} \cos \left(a_{1}-\frac{m \pi}{L}\right) x \cosh a_{2} x\right\}\right] \sin \left(\frac{n y}{R}\right)
\end{aligned}
$$


ただし，

$$
\begin{aligned}
& k^{2}=\left(\frac{E_{y}}{G_{x y}}-2 \nu_{y}\right)\left(\frac{n}{R}\right)^{2}, l^{4}=\frac{E_{y}}{E_{x}}\left(\frac{n}{R}\right)^{4}, m_{1}=\sqrt{\frac{k^{2}+\sqrt{k^{4}-4 l^{4}}}{2}}, m_{2}=\sqrt{\frac{k^{2}-\sqrt{k^{4}-4 l^{4}}}{2}} \\
& H_{1}=\frac{\gamma_{1} B_{1}-\delta_{1} B_{2}}{2\left(\gamma_{1}^{2}+\delta_{1}^{2}\right)}, H_{2}=\frac{\gamma_{2} B_{1}-\delta_{2} B_{2}}{2\left(\gamma_{2}^{2}+\delta_{2}^{2}\right)}, J_{1}=\frac{\delta_{1} B_{1}-\gamma_{1} B_{2}}{2\left(\gamma_{1}^{2}+\delta_{1}^{2}\right)}, J_{2}=\frac{\delta_{2} B_{1}-\gamma_{2} B_{2}}{2\left(\gamma_{2}^{2}+\delta_{2}^{2}\right)} \\
& \left.\delta_{1}=4\left(\alpha_{1}+\frac{m \pi}{2}\right) \alpha_{2}\left\{\left(\alpha_{1}+\frac{m \pi}{2}\right)^{2}-\alpha_{2}^{2}\right\}+\frac{(k L)^{2}}{2}\left(\alpha_{1}+\frac{m \pi}{2}\right) \alpha_{2}\right\} \\
& \left.\delta_{2}=4\left(\alpha_{1}-\frac{m \pi}{2}\right) \alpha_{2}\left\{\left(\alpha_{1}-\frac{m \pi}{2}\right)^{2}-\alpha_{2}^{2}\right\}+\frac{(k L)^{2}}{2}\left(\alpha_{1}-\frac{m \pi}{2}\right) \alpha_{2}\right\} \\
& \gamma_{1}=\left(\alpha_{1}+\frac{m \pi}{2}\right)^{4}-6\left(\alpha_{1}+\frac{m \pi}{2}\right)^{2} \alpha_{2}^{2}+\alpha_{2}^{4}+\left(\frac{k L}{2}\right)^{2}\left\{\left(\alpha_{1}+\frac{m \pi}{2}\right)-\alpha_{2}^{2}\right\}+\left(\frac{l L}{2}\right)^{4} \\
& \left.\gamma_{2}=\left(\alpha_{1}-\frac{m \pi}{2}\right)^{4}-6\left(\alpha_{1}-\frac{m \pi}{2}\right)^{2} \alpha_{2}^{2}+\alpha_{2}^{4}+\left(\frac{k L}{2}\right)^{2}\left\{\left(\alpha_{1}-\frac{m \pi}{2}\right)-\alpha_{2}^{2}\right\}+\left(\frac{l L}{2}\right)^{4}\right\}
\end{aligned}
$$

また, $F_{1}, F_{2}$ は境界条件式(40)より次のようになる。

$$
F_{1}=\frac{m_{2}^{2} Q_{1}-(2 / L)^{2} Q_{2}}{\left(m_{1}^{2}-m_{2}^{2}\right) \cosh \left(m_{1} L / 2\right)}, F_{2}=\frac{(2 / L)^{2} Q_{2}-m_{1}^{2} Q_{1}}{\left(m_{1}^{2}-m_{2}^{2}\right) \cosh \left(m_{2} L / 2\right)}
$$

ただし，

$$
\begin{aligned}
& Q_{1}=\left\{\left(H_{1}-H_{2}\right) \cos \alpha_{1} \sinh \alpha_{2}-\left(J_{1}-J_{2}\right) \sin \alpha_{1} \cosh \alpha_{2}\right\} \sin \left(\frac{m \pi}{2}\right) \cdots \\
& Q_{2}=\left[\left[-\left\{\left(\alpha_{1}+\frac{m \pi}{2}\right)^{2}-\alpha_{2}^{2}\right\} H_{1}-2\left(\alpha_{1}+\frac{m \pi}{2}\right) \alpha_{2} J_{1}+\left\{\left(\alpha_{1}-\frac{m \pi}{2}\right)^{2}-\alpha_{2}^{2}\right\} H_{2}+2\left(\alpha_{1}-\frac{m \pi}{2}\right) \alpha_{2} J_{2}\right] \cos \alpha_{1} \sinh \alpha_{2}\right. \\
& \left.+\left[-2\left(\alpha_{1}+\frac{m \pi}{2}\right) \alpha_{2} H_{1}+\left\{\left(\alpha_{1}+\frac{m \pi}{2}\right)^{2}-\alpha_{2}^{2}\right\} J_{1}+2\left(\alpha_{1}-\frac{m \pi}{2}\right) \alpha_{2} H_{2}-\left\{\left(\alpha_{1}-\frac{m \pi}{2}\right)^{2}-\alpha_{2}^{2}\right\} J_{2}\right] \sin \alpha_{1} \cosh \alpha_{2}\right] \\
& \times \sin \left(\frac{m \pi}{2}\right)
\end{aligned}
$$

式(13)の平衡方程式に応力関数のほか, 各諸値を代入し Galerkin 法を適用すると,

$$
\int_{0}^{2 \pi R} \int_{-L / 2}^{L / 2} I\left(w_{B}\right) \cos \frac{m \pi x}{L} \sin \frac{n y}{R} d x d y=0
$$

となり，上式を解くにあたり時間 $t$ の無次元量 とを導入することにより，Mathieu 形方程式が次式で表される.

$$
\frac{d^{2} b(\zeta)}{d \zeta^{2}}+(\phi+\phi \cos \zeta) b(\zeta)=0
$$

ただし，

$$
\begin{aligned}
& \phi=\phi_{1}=\frac{1}{\Omega^{2}} \frac{h}{R}\left[\left(\frac{R}{L}\right)^{4} \frac{1}{R h^{2}} \frac{D_{11}(m \pi)^{4}+2\left(D_{12}+2 D_{66}\right)(m \pi)^{2}(n L / R)^{2}+D_{22}(n L / R)^{4}}{E_{y}}\right. \\
& \left.+\frac{R}{h} \frac{(m \pi)^{4}}{(m \pi)^{4}+k^{2}(L m \pi)^{2}+(l L)^{4}}+K n^{2} W_{1}\right] \\
& \psi=-\frac{1}{\Omega^{2}} K n^{2} \alpha \frac{h}{R} W_{1}
\end{aligned}
$$

ここで, 式(49) と式(50)にある $W_{1}$ は以下の式で示される，また，上式(48)の中の Mathieu 係数 $\phi, \psi$ は, 円筒殼の 幾何学的形状, 各種剛性值抢よび荷重条件が定まると, $m, n$ だけの関数となるので, $m, n$ を順次変化させそれに 対する安定判別を行う.

$$
\begin{aligned}
W_{1} & =1+\alpha_{2}\left\{\frac{1}{\alpha_{1}^{2}+\alpha_{2}^{2}}-\frac{1}{2} \frac{1}{\left(\alpha_{1}+m \pi\right)^{2}+\alpha_{2}^{2}}-\frac{1}{2} \frac{1}{\left(\alpha_{1}-m \pi\right)^{2}+\alpha_{2}^{2}}\right\}\left(A_{1} \sin \alpha_{1} \cosh \alpha_{2}+A_{2} \cos \alpha_{1} \sinh \alpha_{2}\right) . \\
& +\left\{\frac{\alpha_{1}}{\alpha_{1}^{2}+\alpha_{2}^{2}}-\frac{1}{2} \frac{\left(\alpha_{1}+m \pi\right)}{\left(\alpha_{1}+m \pi\right)^{2}+\alpha_{2}^{2}}-\frac{1}{2} \frac{\left(\alpha_{1}-m \pi\right)}{\left(\alpha_{1}-m \pi\right)^{2}+\alpha_{2}^{2}}\right\}\left(A_{2} \sin \alpha_{1} \cosh \alpha_{2}-A_{1} \cos \alpha_{1} \sinh \alpha_{2}\right) \\
& -\frac{4(m \pi)^{2}}{(m \pi)^{4}+k^{2}(L m \pi)^{2}+(l L)^{4}}\left[\alpha_{2}\left\{\frac{1}{\alpha_{1}^{2}+\alpha_{2}^{2}}-\frac{1}{2} \frac{1}{\left(\alpha_{1}+m \pi\right)^{2}+\alpha_{2}^{2}}-\frac{1}{2} \frac{1}{\left(\alpha_{1}-m \pi\right)^{2}+\alpha_{2}^{2}}\right\}\right. \\
& \times\left(B_{1} \sin \alpha_{1} \cosh \alpha_{2}+B_{2} \cos \alpha_{1} \sinh \alpha_{2}\right) \\
& \left.+\left\{\frac{\alpha_{1}}{\alpha_{1}^{2}+\alpha_{2}^{2}}-\frac{1}{2} \frac{\left(\alpha_{1}+m \pi\right)}{\left(\alpha_{1}+m \pi\right)^{2}+\alpha_{2}^{2}}-\frac{1}{2} \frac{\left(\alpha_{1}-m \pi\right)}{\left(\alpha_{1}-m \pi\right)^{2}+\alpha_{2}^{2}}\right\}\left(B_{2} \sin \alpha_{1} \cosh \alpha_{2}-B_{1} \cos \alpha_{1} \sinh \alpha_{2}\right)\right] \\
& +F_{1}\left(m_{1} L\right)^{2} \frac{m \pi}{(m \pi)^{2}+\left(m_{1} L\right)^{2}} \sin \frac{m \pi}{2} \cosh \frac{m_{1} L}{2}+F_{2}\left(m_{2} L\right)^{2} \frac{m \pi}{(m \pi)^{2}+\left(m_{2} L\right)^{2}} \sin \frac{m \pi}{2} \cosh \frac{m_{2} L}{2}
\end{aligned}
$$


$-\left[H_{1}\left\{\left(\alpha_{1}+\frac{m \pi}{2}\right)^{2}-\alpha_{2}^{2}\right\}+2 J_{1}\left(\alpha_{1}+\frac{m \pi}{2}\right) \alpha_{2}\right]\left[\alpha_{2} \sin \alpha_{1} \cosh \alpha_{2}\left\{-\frac{1}{\left(\alpha_{1}+m \pi\right)^{2}+\alpha_{2}^{2}}+\frac{1}{\alpha_{1}^{2}+\alpha_{2}^{2}}\right\}\right.$

$\left.+\cos \alpha_{1} \sinh \alpha_{2}\left\{\frac{\left(\alpha_{1}+m \pi\right)}{\left(\alpha_{1}+m \pi\right)^{2}+\alpha_{2}^{2}}-\frac{\alpha_{1}}{\alpha_{1}^{2}+\alpha_{2}^{2}}\right\}\right]-\left[J_{1}\left\{\left(\alpha_{1}+\frac{m \pi}{2}\right)^{2}-\alpha_{2}^{2}\right\}-2 H_{1}\left(\alpha_{1}+\frac{m \pi}{2}\right) \alpha_{2}\right]$

$\times\left[\alpha_{2} \cos \alpha_{1} \sinh \alpha_{2}\left\{-\frac{1}{\left(\alpha_{1}+m \pi\right)^{2}+\alpha_{2}^{2}}+\frac{1}{\alpha_{1}^{2}+\alpha_{2}^{2}}\right\}+\sin \alpha_{1} \cosh \alpha_{2}\left\{-\frac{\left(\alpha_{1}+m \pi\right)}{\left(\alpha_{1}+m \pi\right)^{2}+\alpha_{2}^{2}}+\frac{\alpha_{1}}{\alpha_{1}^{2}+\alpha_{2}^{2}}\right\}\right]$

$-\left[H_{2}\left\{\left(\alpha_{1}-\frac{m \pi}{2}\right)^{2}-\alpha_{2}^{2}\right\}+2 J_{2}\left(\alpha_{1}-\frac{m \pi}{2}\right) \alpha_{2}\right]\left[\alpha_{2} \sin \alpha_{1} \cosh \alpha_{2}\left\{-\frac{1}{\left(\alpha_{1}-m \pi\right)^{2}+\alpha_{2}^{2}}+\frac{1}{\alpha_{1}^{2}+\alpha_{2}^{2}}\right\}\right.$

$\left.+\cos \alpha_{1} \sinh \alpha_{2}\left\{-\frac{\left(\alpha_{1}-m \pi\right)}{\left(\alpha_{1}-m \pi\right)^{2}+\alpha_{2}^{2}}-\frac{\alpha_{1}}{\alpha_{1}^{2}+\alpha_{2}^{2}}\right\}\right]-\left[J_{2}\left\{\left(\alpha_{1}-\frac{m \pi}{2}\right)^{2}-\alpha_{2}^{2}\right\}-2 H_{2}\left(\alpha_{1}-\frac{m \pi}{2}\right) \alpha_{2}\right]$

$\times\left[\alpha_{2} \cos \alpha_{1} \sinh \alpha_{2}\left\{-\frac{1}{\left(\alpha_{1}-m \pi\right)^{2}+\alpha_{2}^{2}}+\frac{1}{\alpha_{1}^{2}+\alpha_{2}^{2}}\right\}+\sin \alpha_{1} \cosh \alpha_{2}\left\{-\frac{\left(\alpha_{1}-m \pi\right)}{\left(\alpha_{1}-m \pi\right)^{2}+\alpha_{2}^{2}}+\frac{\alpha_{1}}{\alpha_{1}^{2}+\alpha_{2}^{2}}\right\}\right]$

\section{3. 数值計算例と解析結果の検討}

数値計算例としては，炭素緎維強化プラスチックス

Table 1 Material constants of CFRP

\begin{tabular}{|c|c|c|}
\hline$E_{\mathrm{L}}(\mathrm{GPa})$ & $\mathrm{E}_{\mathrm{T}}(\mathrm{GPa})$ & $\mathrm{G}_{\mathrm{LT}}(\mathrm{GPa})$ \\
\hline 137 & 8.18 & 4.75 \\
\hline$v_{\mathrm{L}}$ & $v_{\mathrm{T}}$ & $\rho\left(\mathrm{kg} / \mathrm{m}^{3}\right)$ \\
\hline 0.316 & 0.0189 & $1.54 \times 10^{3}$ \\
\hline
\end{tabular}

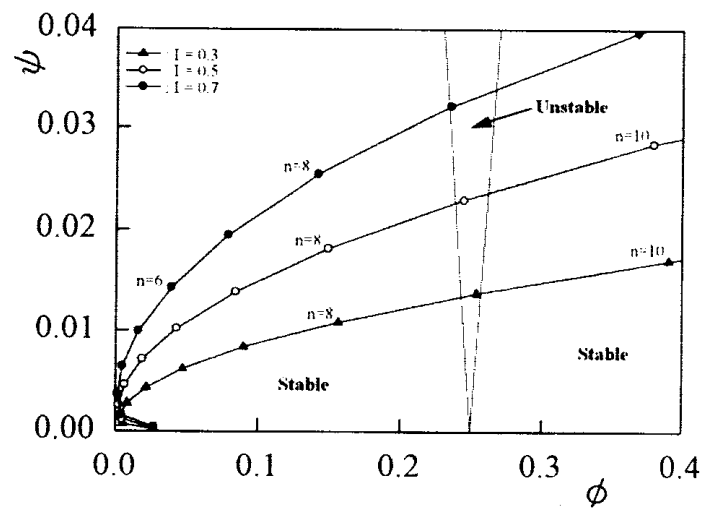

(a) $R / h=50$

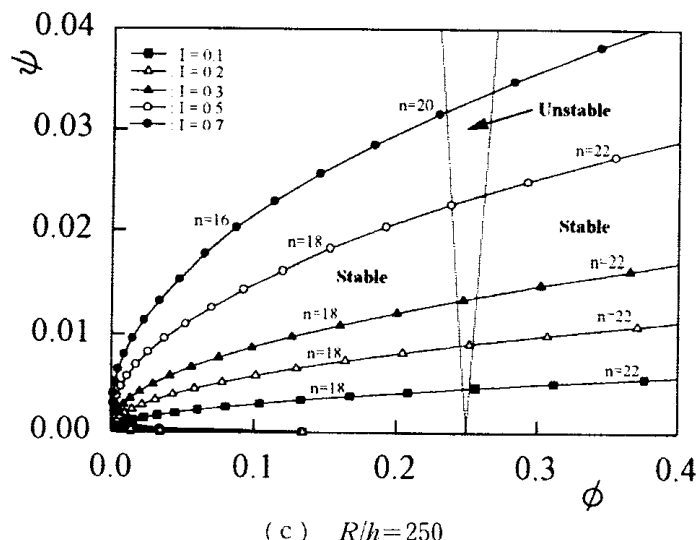

(c) $R / h=250$
(CFRP) 材を考える. その基本の弾性定数(織維容積 含有率 $V_{f}=60 \%$ ) は，平均化近似解法による式(9)によ り計算され，実験でも確かめられた值であり，表 1 に 示守. 式(48)中の $\phi, \phi$ は，円筒款の幾何学的形状，各 種剛性值，鱼荷条件および振動条件などが定まると， $m, n$ だけの関数となる. 永井ら(1)も指摘しているよ うに，筒殼が十分に薄肉の場合には面内および回転 慣性力の影響はいずれも無視することができるので， 本解析モデルの積壓问筒殼は十分に薄肉と考えられる ため，板厚方向すなおち面外慣性力のみを考慮した。

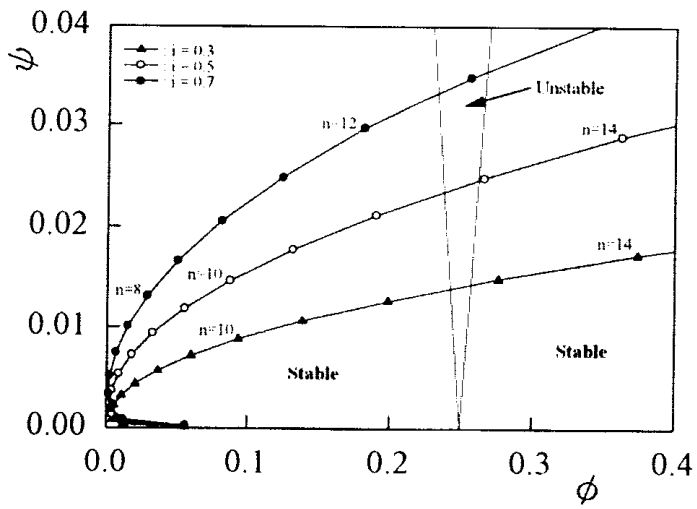

(b) $R / h=100$

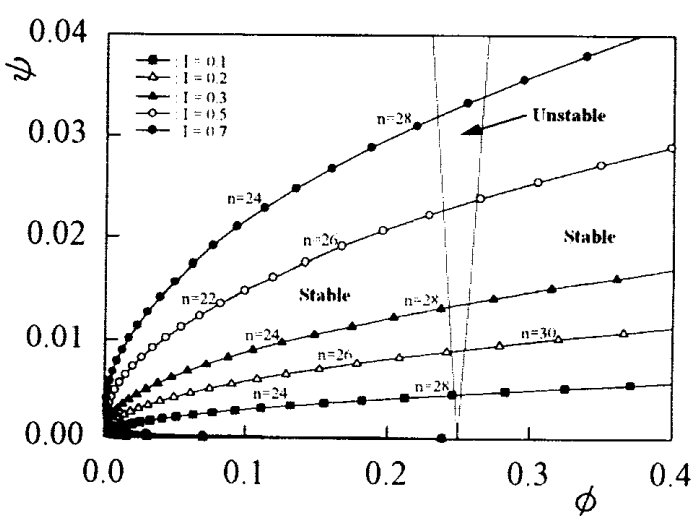

(d) $R / h=500$

Fig. 3 The relation between $\phi$ and $\phi$ for cross-ply laminated cylindrical shells under impact external pressure at $Z=900$ (Number of layers $N=7$, Inner lamination angle $\theta=90$ [deg.]) 
著者の一人が以前に報告した積層円筒殼の外圧座 届 ${ }^{(7)(8)}$ ，振動特性 ${ }^{(10)}$ において軸方向半波数 $m$ は，クロ スプライ積層では, すべての積層数 $N$, 形状パラメー 夕 $R / h, Z$ に無関係に一定值 1 であることを示してい る.そこで, このことを考慮すると, 衝撃外玨力が作 用したとき，固有振動数との連成効果による不安定現 象解析では軸方向半波数 $m$ は 1 で励起すると考えら れるため, 数值計算ては $m=1$ とした. そして, $n$ が

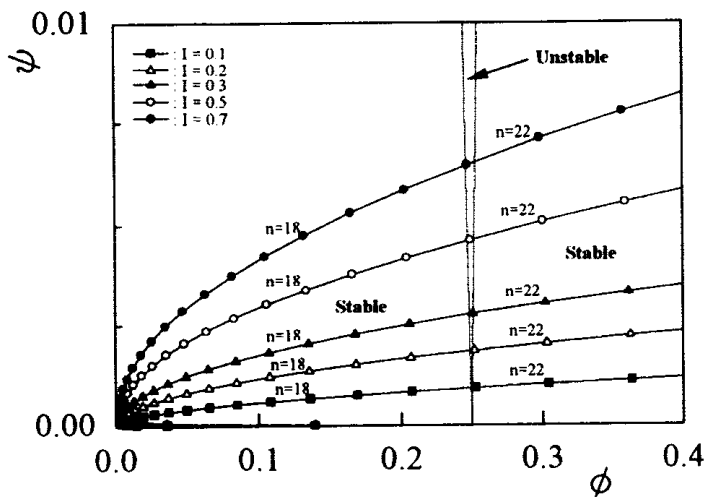

(a) Number of layers $N=3$

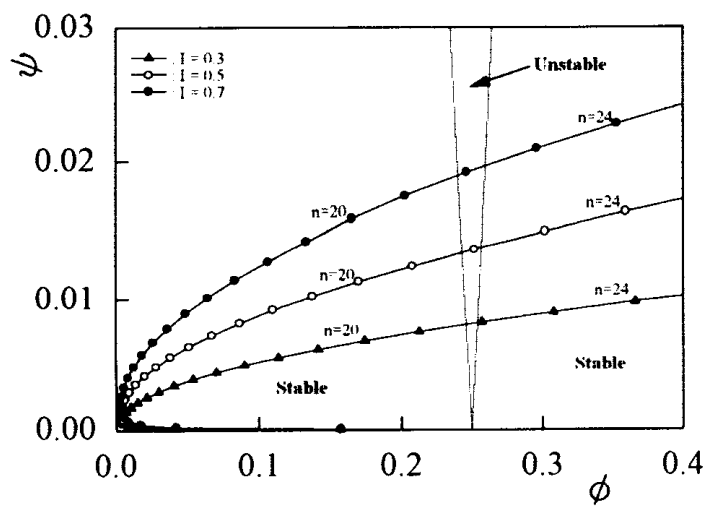

(b) Number of layers $N=7$

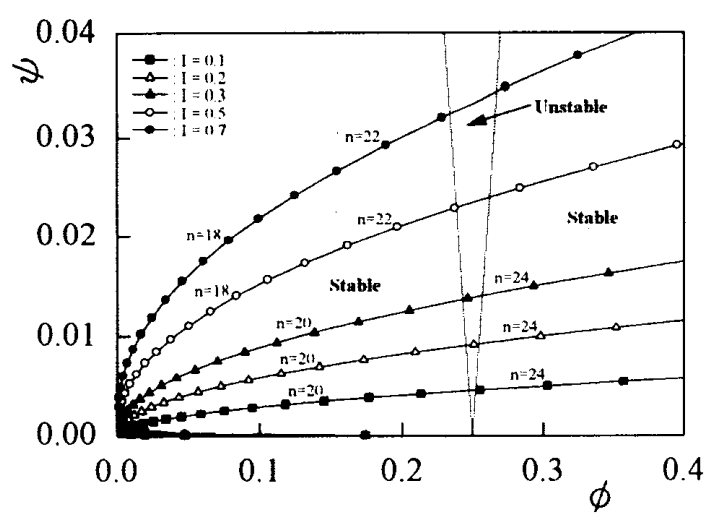

(c) Number of layers $N=\infty$

Fig. 4 The relation between $\phi$ and $\phi$ for cross-ply laminated cylindrical shells under impact external pressure at $R / h=300, Z=900$ (Inner lamination angle $\theta=0[\mathrm{deg}]$.
増加すると $\phi, \phi も 大 き く な り ，$ 放物線状に変化する. 数值計算例の一例として, Mathieu 形方程式の無次 元係数 $\phi, \phi$ の関係について示す. 最内層積層角 $\theta=$ $90^{\circ}$, 形状パラメー夕 $Z\left(=L^{2} / R h\right)=900$ の場合を図 3 に示し $, R / h=50,100,250,500$ と変化させ，その影響 を見るために各図(a)，(b)，(c)，(d)に示してい る.また，最内層積層角 $\theta$ と積層数 $N$ の影響を見る ために形状パラメータ $R / h=300, Z=900$ について,

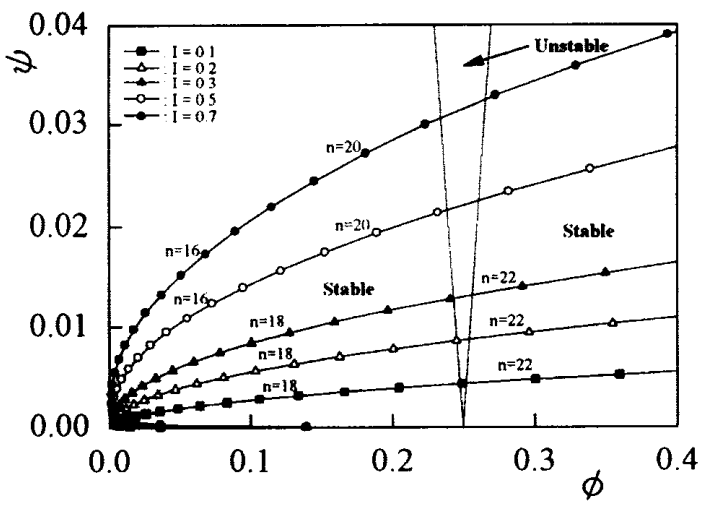

(a) Number of layers $N=3$

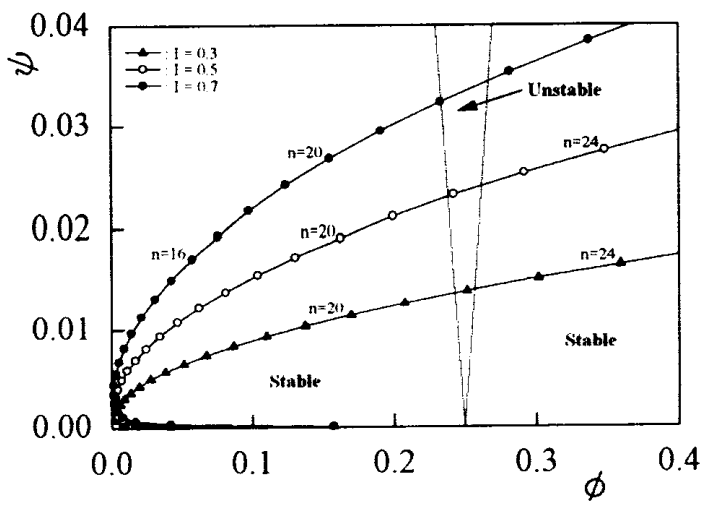

(b) Number of layers $N=7$

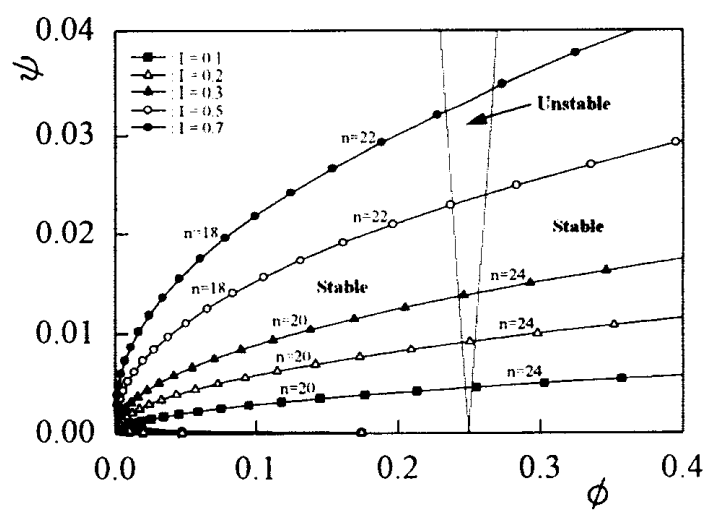

(c) Number of layers $N=\infty$

Fig. 5 The relation between $\psi$ and $\phi$ for cross-ply laminated cylindrical shells under impact external pressure at $R / h=300, Z=900$ (Inner lamination angle $\theta=90$ [deg.]) 
最内層䅡層角を $\theta=0^{\circ}$ と $\theta=90^{\circ}$ とし，それぞれの場 命について, 図 4, 5 に示し, 荷重比 $I$ を 0.1, 0.2, 0.3, $0.5,0.7$ と変化させ, 積層数 $N=3,7, \infty$ 層の場合につ いて各図( a ), (b), (c)に示す.

(1) 形状パラメータR/hの影響 図 3 に示す ように, Mathieu形方程式の係数に及ぼす $R / h$ の影

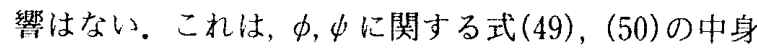
がすべて $R / h$ と $Z$ の関数で整理することができるた め,このような結果になったと思われる、また，他の 積層数, 荷重比においても $R / h$ の変化による傾向は変 わらず, $R / h$ の増加に伴い不安定モードを示す円周方 向波数 $n$ が増加するだけである。

（2）積層数 $N$ と最内層積層角 $\theta$ の影響 洞 4 , 5 に示すように，何重比を一定にすれば，積層数の增 加に伴い，不安定領域を占める円周方向のモードは高 次の不安定モードとなっていく．また，本解析で使用 した境界条件での, クロスプライ積層円筒殼の静的座 屈特性は, 積層数の增加に伴い, 最内層積層角 $\theta=0$ 。 の場合，円周方向波数が減少していくのに対し，最内 層積層角 $\theta=90^{\circ}$ の場合では, 円周方向波数が増加し ていく(8).このことを考えると，静的座屈特性と衝撃 外圧力を受けた場合の動的座屈特性の安定問題におい て, 静的座屈特性については, 積層順序による座屈相 違の関係を考慮することが重要であるが, 円筒殼に衝 慗外压力が作用する場合の不安定領域は最内層積層角 の違いによる影暗はあまり見られない、また，積層数 が增加するに従って, 板原方向に均質な直交異方性の 場合 $(N=\infty)$ に近づき，積層䐓序の影響はなくなる. このことから，静的座屈特性と同様に不安定現象に関 する不安定モードや無次元係数 いる.
（3）荷重比 $I$ の影響 形状パラメータ $R / h$, 最 内層積層角 $\theta$, 積層数 $N$ にかかわらず, 荷重比の增大 に伴い, 不安定領域に現れる円周方向波数は高次の不 安定モードに遷移していく，本解析では最小荷重比を 0.1 の場合まで行っているものがあるが、いずれの場 合もこのように静的座届外圧力よりも低い衝撃外压力 で不安定となるモードが発生している。

\section{4. 結言}

対称クロスプライ積層円筒殼に衝撃外爪力を負荷さ せたときの動的安定性を, Mathieu 形方程式による安 定判別法を用い，座屆前軸対称運動を考慮することで， 静的座㲏值以下でも不安定となる可能性があることを 示した．また，複合材料構造であるために必要な材料 定数をパラメータにするには膨大な図面を必要とする ので代表的な CFRP材について検討した。

なお, 半径方向外圧力と軸方向外圧力を合わせて受 ける静水圧の場合についても同様な解析結果を得てい るが, 紙面の都合で後報に譲ることにする.

\section{文献}

(1) 永弁健一, 八巻昇, 機論, 53-491, C (1987), 1309-1316.

(2) Yao, J. C., AIAA J., 1-6 (1963), 1391-1396.

(3) Bieniek, M. P., Fan, T. C. and Lackman, L. M., AIAA J., 4 -3 (1965), 495-500.

(4) 粕谷平和 - 根本圭一, 機論, 59-558, A (1993)，454-460.

(5) 根本圭--.・粕谷平和, 機論, 60-574, A (1994), 1365-1370.

(6) 粕谷平和・ほ加 2 名, 機論, 61-592, A (1995), 2614-2620.

（7）粕谷平和・植村益次, 材料, 34 378 (1985), 262-266.

（8）粕谷开和・植村登次，日本複合材料学会誌，12-2（1986), 73- 79 .

(9) 梢村益次 - 14田直樹, 材料, 24-257 (1975), 156-163.

(10) 粕谷平和, 東海大学丁.学部紀要, $26 \% 2$ (1986), 89-94. 